Acta technologica agriculturae 3

Nitra, Slovaca Universitas Agriculturae Nitriae, 2013, p. 78-81

\title{
CUTTING PROCESS CAPABILITY STUDY
}

\author{
Katarína LESTYÁNSZKA ŠKŮRKOVÁ, ${ }^{1}$ Jozef ŽARNOVSKÝ2 \\ 'Slovak University of Technology in Bratislava, Slovak Republic \\ ${ }^{2}$ Slovak University of Agriculture in Nitra, Slovak Republic
}

\begin{abstract}
This study focuses on the evaluation of cutting process capability in the production of printed circuit boards according to regulation defined by ISO 9001: 2008 Quality Management Systems. Requirements. Therefore, statistical process control is analysed on the basis of normality and stability of the process, and cutting process capability indices $C_{p}$ and $C_{p k}$ are calculated. The values obtained for indices are $C_{p}=6.801$ and $C_{p k}=5.499$. Therefore, we can consider the process as capable.
\end{abstract}

Keywords: control charts, $C_{p}$ and $C_{p k}$ indices, cutting process capability, process stability, serial production,

The manufacturing organization is situated in Western Slovakia and deals with the manufacturing of electronic components. It was discovered by observations that qualitative errors arise in the manufacturing process. Therefore, it was necessary to implement the statistical control into the cutting process, and the chosen product was the Graetz bridge, which can be seen in Figure 1.

Based on the results of final inspection and frequent customer's complaints, it was discovered that errors in the manufacturing process are caused by components that are cut in the process , material preparing. Therefore, it is required to assure the quality of the manufacturing process within each production phase. The monitoring and

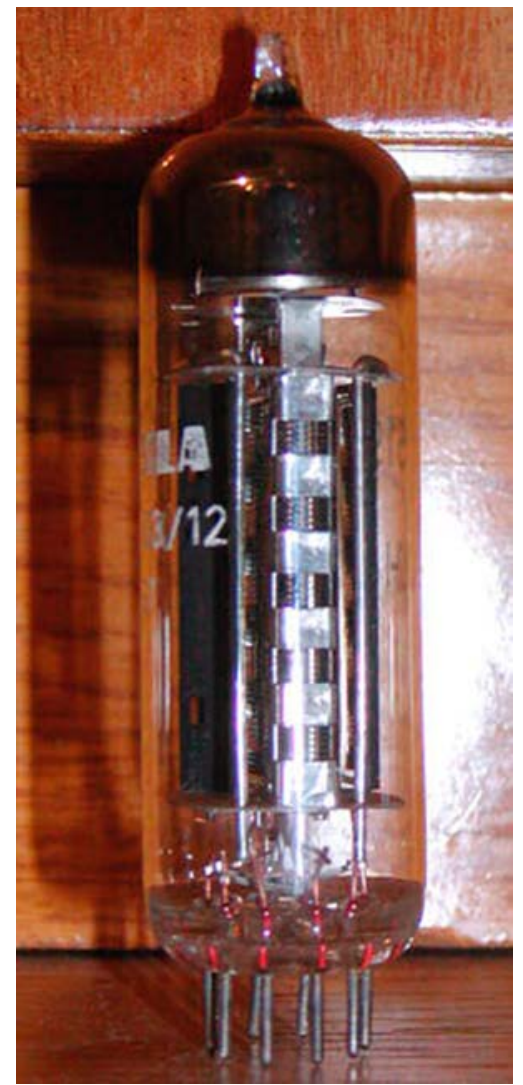

Figure 1

Graetz bridge evaluation of manufacturing process capability presents one of the methods for ensuring and improving processes in the manufacturing organization. It includes the monitoring of stability and normality based on values obtained from the manufacturing process and the calculation of manufacturing process capability indices $C_{p}$ and $C_{p k}$ (Andrássyová et al., 2011).

By determining the process capability, we can isolate the estimated process capability (before starting the production) and permanent process capability. The $C_{p}$ index shows the process variability, and the $C_{p k}$ index shows the position of the process in a tolerance zone (Škưrková, 2009).

The objective of this paper is to monitor the cutting process capability in the production of printed circuit boards (PCB). The process will be checked by the evaluation of control charts for average $\bar{X}$ and range $R$ (STN ISO 8258:1995 Shewhart control charts). If conditions for the evaluation of control charts and for the achievement of cutting process capability are not met, the monitored process shall be subjected to a detailed study immediately, and corrective and preventive measures shall be proposed. If the $C_{p}$ and $C_{p k}$ indices are higher than 1.33, we can consider the process as capable (Hrubec, 2009).

\section{Material and methods}

A dimension of $6.2-7.2 \mathrm{~mm}$ was measured on the PCB. This dimension is considered as the level of safety and requirements of the customer.

\section{Data collecting}

The analysed values of measured parameters are collected from the cutting process of $\mathrm{PCB}$.

We proceeded as follows:

- Measured values were included in subgroups $k=20$, with the subgroup size $n=5$ for every half hour (Table 1).

The measured values are used for the calculation of:

- Average value of attribute in subgroup:

$$
\bar{X}_{i}=\frac{1}{n} \sum_{j=1}^{n} X_{i j}
$$


Table 1 Measured values of the cutting process of PCB

\begin{tabular}{|l||c|c|c|c|c|}
\hline & $\mathbf{n 1}$ & $\mathbf{n 2}$ & $\mathbf{n 3}$ & $\mathbf{n 4}$ & $\mathbf{n 5}$ \\
\hline \hline $\mathrm{k}$ & 1 & 2 & 3 & 4 & 5 \\
\hline 1 & 6.60 & 6.62 & 6.65 & 6.63 & 6.59 \\
\hline 2 & 6.58 & 6.57 & 6.60 & 6.61 & 6.59 \\
\hline 3 & 6.56 & 6.62 & 6.60 & 6.58 & 6.60 \\
\hline 4 & 6.58 & 6.66 & 6.64 & 6.64 & 6.63 \\
\hline 5 & 6.63 & 6.59 & 6.63 & 6.62 & 6.60 \\
\hline 6 & 6.58 & 6.60 & 6.62 & 6.63 & 6.58 \\
\hline 7 & 6.62 & 6.59 & 6.58 & 6.64 & 6.63 \\
\hline 8 & 6.55 & 6.62 & 6.61 & 6.61 & 6.60 \\
\hline 9 & 6.60 & 6.57 & 6.60 & 6.62 & 6.61 \\
\hline 10 & 6.59 & 6.61 & 6.65 & 6.60 & 6.59 \\
\hline 11 & 6.57 & 6.60 & 6.63 & 6.64 & 6.59 \\
\hline 12 & 6.60 & 6.57 & 6.56 & 6.62 & 6.62 \\
\hline 13 & 6.60 & 6.63 & 6.57 & 6.62 & 6.58 \\
\hline 14 & 6.63 & 6.60 & 6.62 & 6.63 & 6.60 \\
\hline 15 & 6.59 & 6.57 & 6.60 & 6.62 & 6.60 \\
\hline 16 & 6.57 & 6.60 & 6.63 & 6.60 & 6.57 \\
\hline 17 & 6.60 & 6.61 & 6.57 & 6.59 & 6.64 \\
\hline 18 & 6.57 & 6.63 & 6.63 & 6.60 & 6.61 \\
\hline 19 & 6.60 & 6.58 & 6.63 & 6.59 & 6.60 \\
\hline 20 & 6.63 & 6.62 & 6.60 & 6.61 & 6.57 \\
\hline
\end{tabular}

Source: Jarabová, 2013

where:

$i-1,2, \ldots, k$ - sequential number of subgroup

$j-1,2, \ldots, n-$ sequential number of measured value in subgroup

$k$ - number of subgroups,

$n$ - subgroup size,

$X_{i j} \quad$ - measured value in the $i$-th subgroup.

\section{- Range in subgroup:}

$$
R_{i}=\operatorname{MAX}\left(X_{i j}\right)-\operatorname{MIN}\left(X_{i j}\right)
$$

where:

$\operatorname{MAX}\left(X_{i j}\right)$ and $\operatorname{MIN}\left(X_{i j}\right)$ - the maximum and minimum value measured in the $i$-th subgroup

Averages $\bar{X}_{j}$ and ranges $R_{i}$ are plotted into control charts. Points are linked by lines to visualise the groups and trends.

\section{- Average of process:}

$$
\overline{\bar{X}}=\frac{1}{k} \sum_{i=1}^{k} \bar{X}_{i}
$$

where:

$i-1,2, \ldots, k$ - sequential number of subgroup

\section{- Average range:}

$$
\bar{R}=\frac{1}{k} \sum_{i=1}^{k} R_{i}
$$

where:

$R_{i}, X_{i}$ - ranges and averages in the $i$-th subgroups $(i=1$, $2, \ldots, k)$

Upper and lower control limits for range and average:

- For range:

$$
\begin{aligned}
& U C L_{R}=D_{4} \times \bar{R} \\
& L C L_{R}=D_{3} \times \bar{R}
\end{aligned}
$$

- For average:

$$
\begin{aligned}
U C L_{\bar{X}} & =\overline{\bar{X}}+A_{2} \times \bar{R} \\
L C L_{\bar{X}} & =\overline{\bar{X}}-A_{2} \times \bar{R}
\end{aligned}
$$

where:

$D_{4}, D_{3}$ and $A_{2}$ are the constants of control limits; they are changing depending on subgroup size from 2 to 25 , the values $A_{2}=0.577, D_{3}=0.000, D_{4}=2.114$ conform to the size $n=5$ (STN ISO 8258:1995; Korenko, 2012)

\section{Plotting and evaluation of control charts for average $\bar{X}$ and range $R$}

Calculated values are used for plotting the control charts for average and range, which are analysed and evaluated after that. The cutting process is statistically controlled when its variability is caused by random causes only (Konstanciak, 2012). If the cutting process is affected by definable causes, it is necessary to determine the causes of negative effects and corrective measures leading to the achievement of process stability (Markulik, 2009).

\section{Production process capability}

We can evaluate the cutting process capability if the following conditions are met:

- process is statistically controlled (stable),

- measured values from the process are characterised by normal distribution,

- technical and other specifications are defined by customer requirements,

- nominal value is located in the centre of tolerance range (Ulewicz, 2001).

Values of cutting process capability are expressed by the capability indices $C_{p}$ and $C_{p k}$. Before starting to calculate the process capability indices, process standard deviation must be estimated.

- Estimation of process standard deviation:

$$
\hat{\sigma}=\frac{\bar{R}}{d_{2}}
$$

where:

$\bar{R} \quad$ - average range in subgroups

$d_{2}$ - constant of a central line, changing according to subgroup size from 2 to 25 , the value $d_{2}=2.326$ corresponds to $n=5$ (STN ISO 8258:1995; Korenko, 2012) 
- Process capability index $C_{p}$ :

$$
C_{P}=\frac{U S L-L S L}{6 \times \hat{\sigma}}=\frac{T}{6 \times \hat{\sigma}}
$$

where:

USL, $L S L$ - upper and lower specification limits

$T \quad$ - tolerance of attribute

- Corrected process capability index $C_{p k}$ :

$$
\begin{gathered}
C_{P K}=\frac{U S L-\overline{\bar{X}}}{3 \times \hat{\sigma}} \\
C_{P K}=\frac{\overline{\bar{X}}-L S L}{3 \times \hat{\sigma}}
\end{gathered}
$$

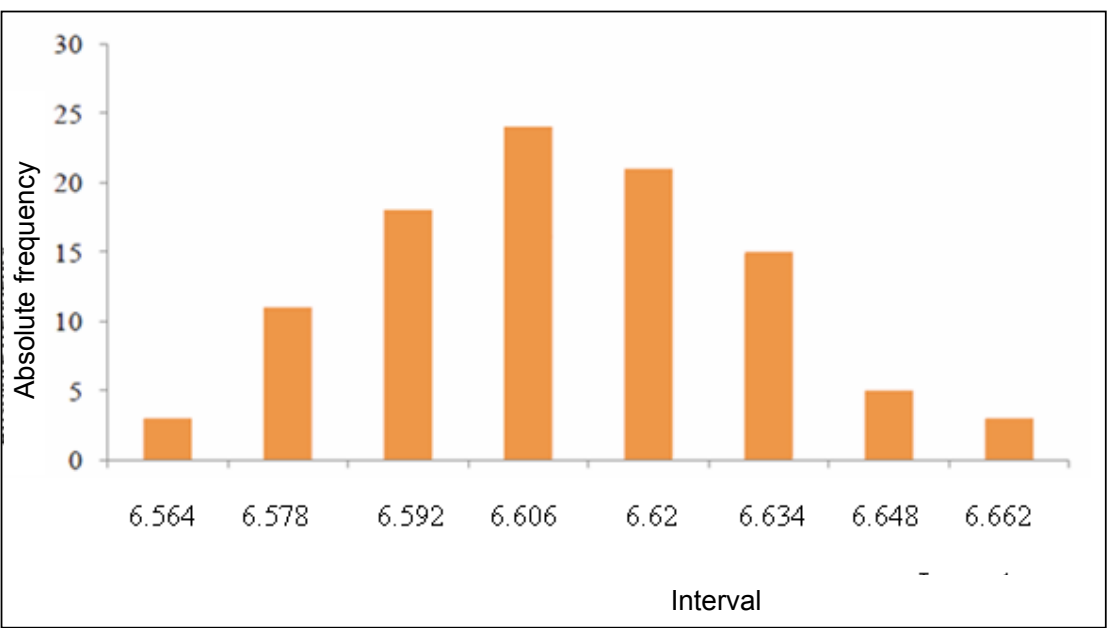

Figure 2 Histogram

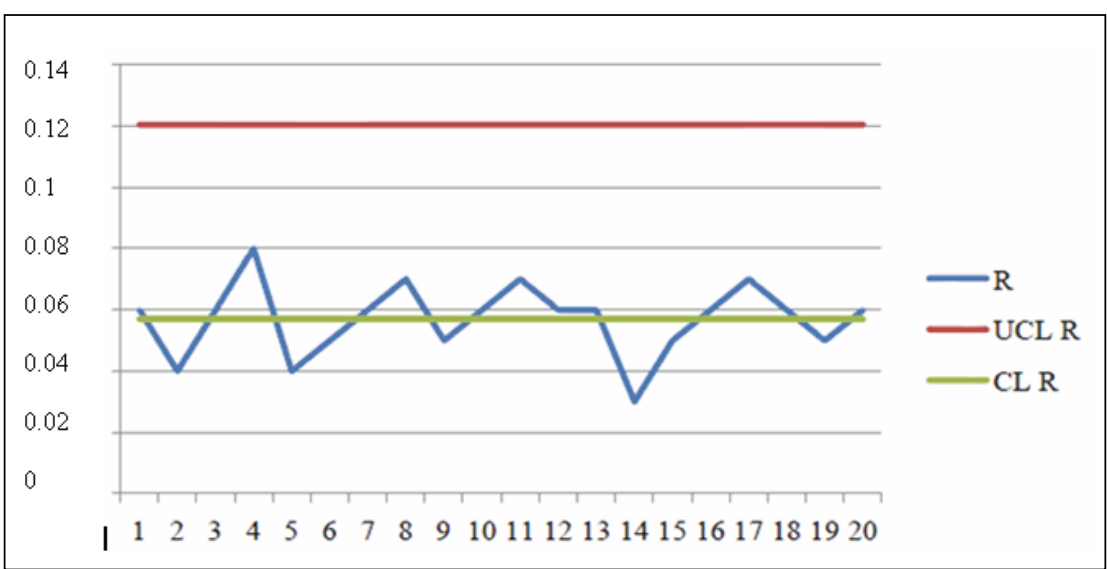

Figure 3 Control chart for range $R$

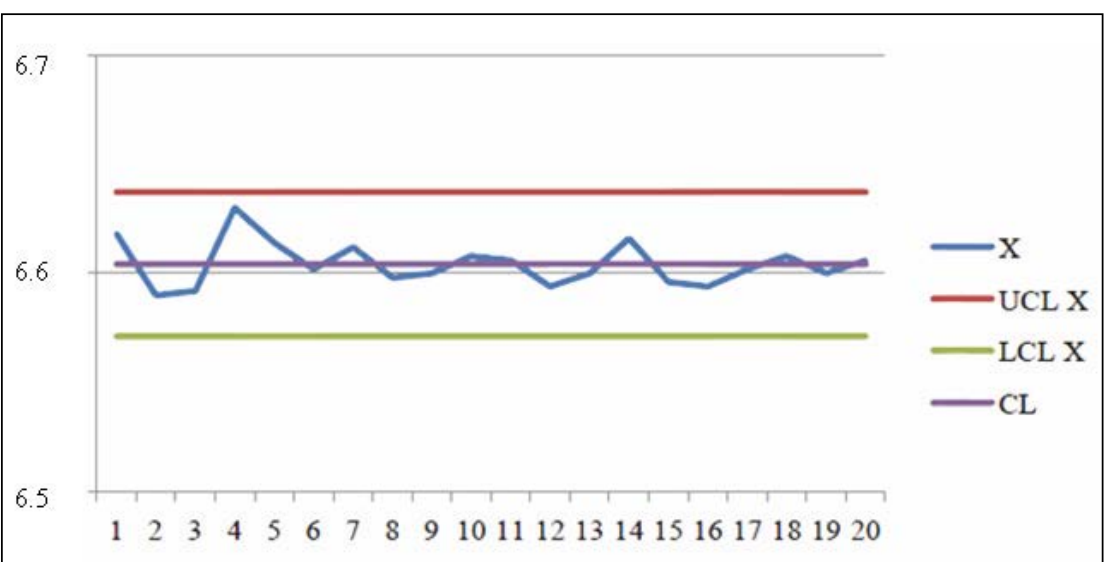

Figure 4 Control chart for average $\bar{X}$
The resulting cutting process indices must meet the previously specified condition $\left(C_{p} \geq 1.33\right.$ and $\left.C_{p k} \geq 1.33\right)$, which can be corrected by the given organization according to internal requirements (cannot be lower).

\section{Results and discussion}

The cutting process of PCB was statistically evaluated for individual parameters of each characteristic. Calculation was carried out by means of Microsoft Excel, using data collected from the manufacturing process with quality control. Values from the process were tested with respect to normal distribution, which was confirmed, as can be seen in Figure 2 (histogram).

The measured values presented in the histogram show that the process is in statistical control and, in this case, we can construct the control charts.

The values of range $R_{i}$ and primarily their location within control limits were analysed on the basis of the control chart for range $R$. Based on analysed variability, the cutting process was stable. Therefore, the evaluation of the control chart for average $\bar{X}$ was performed. In Figure 3 ( $R$ chart), we can see the values for range $R$, and the average values for measured data are shown in Figure 4 ( $\bar{X}$ chart).

We have obtained the following values:

- $\overline{\bar{X}}=6.6043$

- $\bar{R}=0.0570 \mathrm{~mm}$

- $U C L_{\mathrm{x}}=6.637 \mathrm{~mm}$

- $L C L_{x}=6.571 \mathrm{~mm}$

- $U C L_{R}=0.120 \mathrm{~mm}$

- $L C L_{R}=0 \mathrm{~mm}$

The control chart for average $\bar{X}$ shows the position of the cutting process. The cutting process was statistically controlled and therefore stable (Jarabová, 2013).

The control chart for average $\bar{X}$ and for range $R$ shows that the cutting process of PCB is in statistical control and each point is within the control limits. We can also consider that the process is influenced by random effects only.

Based on these findings, we can start with calculating the indices $C_{p}$ and Cpk. The calculated values are $C_{p}=6.801$ and $C_{p k}=5.499$. 
Based on these values, we can consider the cutting process as stable because both values are higher than 1.33.

\section{Conclusion}

The methods of statistical process control and evaluation of cutting process capability verify an ability of the process to meet the defined requirements of product quality. Cutting process capability showed that the process provides products satisfying demanding quality criteria and customer requirements. As regards statistical control, the indices $C_{p}=6.801$ and $C_{p k}=5.499$ were obtained. Therefore, we can consider the process as capable.

\section{Acknowledgement}

This paper was prepared with the support of the projectVEGA No 1/0448/13,Transformation of ergonomic programme into management structure through integration and utilization of QMS, EMS, HSMS'.

\section{References}

ANDRÁSSYOVÁ, Z. et al. 2011. Assembly process capability of automotive seats. In Acta Technologica Agriculturae, vol. 14, 2011, no. 3, pp. 74-78.

HRUBEC, J. et al. 2009. Integrovaný manažérsky systém. Nitra : SPU. ISBN 978-80-552-0231-0.

JARABOVÁ, D. 2013. Aplikácia štatistickej regulácie procesu strihania vývodov komponentov (diploma thesis). Trnava : STU.
KONSTANCIAK, M. 2012. Analysis of technological strategies on the example of the production of the tramway whels. In: Archives of Materials Science and Engineering, vol. 57, 2012, no. 2, pp. 69-74.

KORENKO, M. 2012. Manažérstvo kvality procesov. Nitra : SPU. ISBN 978-80-552-0789-6.

MARKULIK, Š. - NAGYOVÁ, A. 2009. Systém manažérstva kvality. Košice : TU. ISBN 978-80-553-0306-2.

ŠKŮRKOVÁ, K. - ŠESTÁK, M. 2009. The capability of turning process by screws production. In Production Engineering. Novosibirsk : Novosibirsk State Technical University, 2009, pp. 49-56. ISBN 978-5-7782-1165-0.

STN EN ISO 8258. 1995 (010271). Shewhart control charts.

STN EN ISO 9001. 2009. Quality management systems. Requirements.

ULEVICZ, R. - BORKOWSKI, S. 2001. The Quality System According to the Norm Qs-9000, W: MT01. The Third International Conference. Mechanical Engineering Technologies, Sofia, S. III. 70.

\section{Contact address:}

Ing. Katarína Lestyánszka Škůrková, PhD., Slovak University of Technology in Bratislava, Institute of Industrial Engineering, Management and Quality, Faculty of Materials Science and Technology in Trnava, Paulínska 16, 91724 Trnava, Slovak Republic, e-mail: katarina.skurkova@stuba.sk 